\title{
Transformações nas relações coletivas de trabalho: por uma concepção democrática de sindicalismo
}

\author{
Clerilei A. Bier*
}

\begin{abstract}
Sumário: Introdução; 1 . As tendências de transformações e de crise no direito do trabalho e a descoletivização das relações laborais; 2. A difícil ruptura do sindicalismo brasileiro com o modelo corporativista; 2.1 As diversas iniciativas de reforma do sistema sindical brasileiro; 3 . Uma nova concepção de sindicalismo assente na cidadania e democracia participativa. Considerações finais. Referências.
\end{abstract}

\begin{abstract}
Resumo: O texto analisa a urgente necessidade de mudança e democratização do modelo brasileiro de relações coletivas de trabalho face às transformações, crise e descoletivização do direito do trabalho, e à manutenção do modelo sindical corporativista vigente no Brasil, bem como algumas propostas de reforma do sistema sindical surgidas nos últimos anos e as alterações por elas pretendidas, especialmente em relação à liberdade sindical. Destaca que o único consenso obtido foi que o mesmo não cumpre mais sua finalidade, devendo ser necessariamente repensado, e propõe que no bojo das discussões sobre renovação do modelo sindical e do sistema negocial brasileiros se tente inserir uma nova concepção de sindicalismo, assente na idéia de solidariedade, emancipação social e democracia participativa.
\end{abstract}

Palavras-chave: Reforma sindical; Cidadania; Democracia participativa.

\begin{abstract}
The current text analyses the urgent need for change and democratization of the Brazilian model of collective bargaining in the industries and labor relations, in the face of crises, transformations deunionizing of labor laws and the maintenance of the union corporativism model current in Brazil as well as some proposals for reform of the system put forward in recent years and the alterations they intended to make especially in relation to unionization freedom. It stresses the fact that theonly consensus reached is that it no longer fullfils its orinal purpose and that it necessarily needs some rethinking. It also considers that central to the arguments on the renewal of the Brazilian model of unionism and system of negotiations an attempt is made to introduce a new concept of syndicalism committed to the idea of solidarity, social emancipation and participative democracy.
\end{abstract}

Keywords : Syndical reform; Social emancipation; Participative democracy.

\section{Introdução}

A necessidade de mudança no modelo brasileiro de relações de trabalho é uma constante que não se conseguiu levar a termo ao longo dos últimos anos. A demo-

\footnotetext{
* Doutora em Direito pela Universidad Complutense de Madrid. Pós-Doutora pela University of Technology Sydney. Professora da ESAG/UDESC.
} 
cratização de nosso sistema jurídico de relações trabalhistas faz-se necessária há muitas décadas, já que fundamentalmente este sistema, de matriz ideológica corporativista, foi concebido para desenvolver um sistema legalista minucioso e tutelar no âmbito das relações individuais de trabalho. Por outro lado, ao estar permeado por uma tônica repressora e intervencionista no tocante às relações coletivas de trabalho, objetivando restringir a livre organização sindical e inibir o desenvolvimento de um sistema negocial efetivo, faz com que prevaleçam as interferências dos poderes Executivo e Legislativo, em detrimento da participação dos interlocutores sociais.

Por não haver sido implementadas as mudanças necessárias para sua democratização no devido momento histórico (décadas de 1950 e 1960, quando houve um crescimento generalizado nas economias, com o conseqüente crescimento no Estado de Bem-Estar Social, propiciado pelas inúmeras conquistas trabalhistas e pelo aumento das garantias e dos direitos dos trabalhadores), nos encontramos hoje frente a uma problemática muito mais complexa, ante a qual qualquer proposta apresenta dificuldades para ser implementada, haja vista que enfrentamos não só um momento economicamente desfavorável como de profundas mudanças no mundo do trabalho, o que dificulta sobremaneira a concretização de tais alterações. Permanece, no entanto, a urgente necessidade de alterar este sistema jurídico, não só em face da necessidade de democratizá-lo, mas agora também para fazer frente a uma série de modificações estruturais nos sistemas de relações de trabalho, decorrentes de fatores políticos, sociais e econômicos. São estas modificações, tão prementes no atual contexto, com diversas implicações tanto positivas como negativas, que se faz necessário analisar com mais profundidade.

\section{As tendências de transformações e de crise no direito do trabalho e a descoletivização das relações laborais}

Nas últimas décadas, diversos foram os acontecimentos relevantes de ordem econômica, social e política que incidiram sobre o sistema de relações de trabalho. Em decorrência das modificações havidas, surgiram questionamentos a respeito de alguns princípios normativos, mais especificamente no âmbito do Direito do Trabalho, trazendo em seu bojo uma discussão que perpassa os principais elementos que compõem tanto o Direito Individual como o Direito Coletivo de Trabalho, bem como seus principais reflexos neste contexto de transformações.

Iniciando com a crise econômica do início da década de 1970, a incidência das modificações demográficas, a estagnação da capacidade de consumo dos países desenvolvidos, a modificação dos processos produtivos em decorrência da necessi- 
dade de maior eficiência, competitividade e produtividade com redução de custos, a mudança na gestão da mão-de-obra e a adoção de novos sistemas gerenciais e organizacionais, capazes de responder às novas necessidades da economia globalizada e da nova ordem internacional (crise do sistema fordista/taylorista, com a emergência de um novo modelo, o da especialização flexível, que se apóia na produção de pequenas e médias empresas com alto grau de flexibilidade e subcontratação), passando pelas necessidades de adaptação e implementação das novas tecnologias, da informática e da robótica, chegamos ao problema do desemprego estrutural e suas graves conseqüências.

Todas estas transformações provocaram a necessidade de reestruturação das relações de trabalho, flexibilizando e muitas vezes precarizando o mercado de trabalho através de novas modalidades de contratação, trabalho em tempo parcial, tele-trabalho e trabalho subcontratado ou terceirizado, sem falar no aumento da parcela de trabalhadores que integra a economia informal, configurando um mercado de trabalho extremamente diferenciado e complexo. ${ }^{1}$ Tais mudanças nos levaram, em última análise, a ampliar e diversificar os questionamentos a que nos vemos expostos, acentuando "as características de exclusão econômica e social do sistema capitalista, recriando condições aparentemente superadas durante os anos dourados do pós-guerra" e afetando o "conjunto do mundo do trabalho: suas relações no interior do processo produtivo, a divisão do trabalho, o mercado do trabalho, o papel dos sindicatos, as negociações coletivas e a própria sociabilidade de um sistema baseado no trabalho," ${ }^{2}$ obrigando-nos a buscar novas alternativas e soluções para enfrentar a fratura do compromisso social e das relações/instituições econômicas, sociais e políticas definidas pelo anterior paradigma industrial e tecnológico.

Mais especificamente no âmbito do Direito de Trabalho, muitos são os reflexos e conseqüências de todo o referido acima. Passamos, a partir da década de 1980, a adotar uma nova postura dentro deste ramo do Direito, que, de eminentemente protetor dos trabalhadores inseridos no mercado formal de trabalho, passa então a preocupar-se também com o cada vez maior número de trabalhadores informais, subempregados e especialmente com os desempregados.

Essa preocupação se traduz especificamente na busca de uma maior flexibilização e desregulamentação das normas trabalhistas, no intento de responder

\footnotetext{
${ }^{1}$ Ver a respeito, entre outros, RIFKIN, J. O fim dos empregos. O declínio inevitável dos níveis dos empregos e a redução da força global de trabalho. São Paulo: Makron, 1995, p. 102-113; FREITAS JR.

A. R. Globalização, mercosul e crise do estado-nação. Perspectiva para o direito numa sociedade em mudança. São Paulo: LTR, 1997, p. 64-68; PAULA LEITE, M. Reestruturação produtiva, novas tecnologias e novas formas de gestão de mão de obra. In: ALONSO DE OLIVEIRA et alli (org.). $\mathbf{O}$ mundo do trabalho. Crise e mudança no final do século. São Paulo: Página Aberta, 1994, p. 563 e ss. ${ }^{2}$ MATOSO, E. J. L. O novo e inseguro mundo do trabalho nos países avançados. In: ALONSO DE OLIVEIRA C. et alli (org.). O mundo do trabalho. Op. cit., p. 522
} 
às novas necessidades surgidas num contexto de relações de trabalho altamente mutável, obtendo-se por vezes resultados questionáveis desde uma ótica eminentemente humanista e preocupada com a justiça social.

Neste momento não se pretende analisar os reflexos da introdução de medidas flexibilizadoras no nosso ordenamento jurídico, ${ }^{3}$ mas tão-somente iniciar, a partir desta reflexão, uma análise a respeito da desregulamentação pretendida no âmbito do Direito Coletivo do Trabalho e das necessárias modificações no nosso sistema de relações coletivas de trabalho para enfrentar este contexto de profundas transformações políticas, econômicas e sociais e, ainda, de adaptação aos autênticos princípios democráticos. ${ }^{4}$

A atual configuração do mercado de trabalho - como já dito, extremamente diferenciado e complexo em função destas grandes transformações sofridas - provocou uma intensa discussão sobre a necessidade de uma reestruturação das relações de trabalho. A flexibilidade e a desregulamentação demandadas, em razão de

${ }^{3}$ Análise mais detalhada a respeito In: BIER, C. A. Direito do trabalho e flexibilização do mercado: a garantia do emprego. In: SEVERO ROCHA. L. (org.). Teoria do direito e do estado. Porto Alegre: Sérgio Antônio Fabris, 1994. p. 17-23.

${ }^{4}$ Para compreender o porquê desta distinção prévia entre os termos flexibilização e desregulamentação, necessário se faz analisar o significado de tais termos no bojo desta discussão, já que entendo, de acordo com Amauri Mascaro Nascimento, que ambas as expressões se distinguem quanto ao âmbito a que se referem, e segundo o qual flexibilização refere-se ao Direito Individual de Trabalho, enquanto desregulamentação diz respeito ao Direito Coletivo do Trabalho. Flexibilização, neste sentido, pode vir a significar, por um lado, a adoção de medidas que pretendam introduzir modificações e adaptações nas normas trabalhistas, tendentes a um reajuste do mercado de trabalho, facilitando a criação quantitativa de empregos, a melhora na qualidade da força de trabalho e uma maior adaptabilidade dessa força de trabalho às expectativas e possibilidades de trabalho (tais como as medidas de distribuição de trabalho, v. g. redução da jornada de trabalho, adoção da jornada flexível de trabalho - distribuição semanal/anual -, restrição e encarecimento das horas extraordinárias, maior mobilidade funcional, aposentadorias compulsórias e/ou antecipadas etc.), e, por outro lado, pode ainda vir a significar a adoção de medidas que não podem deixar de originar uma contínua degradação da situação do emprego, e de alguns dos princípios básicos e tradicionais em que se havia assentado o Direito do Trabalho (tais como as medidas que buscam aumentar as faculdades de livre disposição empresarial sobre o uso da força de trabalho - liberalização do regime de despedimento -, ou que dizem respeito às novas modalidades de contratação temporal e possibilitam a degradação da posição do trabalhador no contrato de trabalho e a debilidade das organizações sindicais - contratos temporários, a tempo parcial, terceirização e cooperativas de serviços, em fraude aos direitos trabalhistas). Desregulamentação, por sua vez, seria a política legislativa de redução de interferência da lei nas relações coletivas de trabalho, para que se desenvolvam segundo o princípio da liberdade sindical e a ausência de leis do Estado que dificultem o exercício desta liberdade - o que permite maior desenvoltura do movimento sindical para, através de ações coletivas, pleitear novas normas e condições de trabalho, em direto entendimento com os representantes empresariais. Nesse sentido, a desregulamentação pode ser um instrumento por excelência para introduzir medidas flexibilizadoras, sejam estas de adaptação ou de desproteção. MASCARO NASCIMENTO, A. Questões atuais de direito do trabalho. Revista LTR, São Paulo, v. 61, n. 1, p. 15-17, jan. 1997; BIER, C. A. Op. cit. p. 19-21. 
todas as transformações mencionadas, não trouxeram como conseqüência apenas a questão da precarização do vínculo de trabalho, mas atingiram de modo inusitado e especial às relações coletivas de trabalho, na medida em que fragmentaram e heterogeneizaram a classe trabalhadora.

Todas estas mudanças verificadas no mundo do trabalho, conforme detalhada análise realizada por Freitas Jr., "entreabriram um itinerário de crise jamais vista na história do sindicalismo. Uma crise que se manifesta quer sob o ângulo da capacidade de arregimentação, quer sob aquele do arrefecimento de seu poder conflitual". ${ }^{5}$

O movimento sindical teve sua gênese no período de desenvolvimento do capitalismo industrial, conforme destaca Athayde Chaves,

[...] quando da adoção dos modelos produtivos ensejadores de grandes concentrações de operários nas indústrias emergentes (v.g. fordismo/taylorismo), o que possibilitou a emergência de uma consciência de classe por parte dos trabalhadores, unida pelo elo da homogeneidade profissional, com a conseqüente 'comunhão de interesses' $[. .$.$] da qual emergiram como forças primeiras do movimento$ sindical, categorias como a dos trabalhadores do setor têxtil, carvoeiro, metalurgia pesada, etc. ${ }^{6}$

A intensa fragmentação e a complexidade do tecido sociolaboral, decorrentes das modificações no mundo do trabalho já mencionadas, especialmente da precarização do trabalho e das novas formas de trabalho oriundas das novas tecnologias, "cria um enorme leque de novas e diversas ocupações, acaba por dificultar, e até aniquilar, qualquer possibilidade de identidade operária", porquanto distanciam os obreiros quanto à aspiração por uma comunhão de interesses. E, com o aumento do abismo social no interior da classe trabalhadora,

[...] reduz-se fortemente o poder sindical, historicamente vinculado aos trabalhadores estáveis, e até agora incapaz de aglutinar os trabalhadores parciais, temporários, precários, da economia informal etc. Com isso começa a desmoronar o sindicalismo vertical, herança do fordismo e mais vinculado à categoria profissional, mais corporativo. ${ }^{7}$

A perda da dimensão coletiva nas relações laborais decorrente desta precarização da estrutura contratual laboral em que assentava o pacto fordista fica patente, segundo Ferreira, ao analisar a variável padrão "representação" no modelo

${ }^{5}$ FREITAS JR., A.R. Op. cit. p. 66.

${ }^{6}$ ATHAYDE CHAVES, L. As mudanças no mundo do trabalho e seus reflexos sobre a atmosfera sindical. Trabalho \& Doutrina. São Paulo, n. 15, p. 71, dez./1997.

${ }^{7}$ Ibidem, p. 71-72. 
clássico do direito do trabalho, que passa do recuo e participação da "voz" coletiva no mercado de trabalho, proteção do reconhecimento como parceiro social, proteção do diálogo social através dos sindicatos livres e independentes e associações de empregadores, direito à greve e direito de informação, participação e consulta, a dar lugar à tensão negativa, com o não-reconhecimento dos direitos sindicais e de participação, e o não-reconhecimento do direito de greve. ${ }^{8}$

A descoletivização e o recuo da voz coletiva sobressaem, segundo o autor, quando tomamos por referência, por um lado, as transformações das formas de produção (transição do paradigma fordista ou da produção, para o pós-fordista ou da especialização flexível) e, por outro, as transformações sentidas pelo sistema de relações industriais (segmentação e dualidade dos mercados de trabalho, desintegração da negociação coletiva e enfraquecimento dos sindicatos). ${ }^{9}$

Em conseqüência do exposto, o sindicalismo passou a perder não só o prestígio e o poder real de barganha como, principalmente, associados, causando

[...] uma verdadeira crise de representatividade no seio do movimento sindical, cuja atuação, a cada dia, tem revelado tendência à inspiração muito mais para um sindicato defensivo ou de participação, que objetiva quando muito a garantia do emprego, submetendo-se cada vez mais às exigências do capital. ${ }^{10}$

\section{A difícil ruptura do sindicalismo brasileiro com o modelo corporativista}

O cenário de crise aqui exposto, que exige um sindicalismo em sintonia com os desafios que o mundo globalizado apresenta, agrava-se muito mais em países como o Brasil, cujo modelo de organização sindical é, por um lado, organizado com base na chamada categoria profissional, com estrutura hierarquizada e piramidal de Federações e Confederações, a qual impossibilita a organização horizontal (da qual estão excluídas as Centrais Sindicais), enquanto conserva, por outro lado, uma estrutura corporativa com grande dependência do Estado, tanto em relação ao monopólio de representação (Unicidade Sindical) quanto no tocante à dependência em relação a sua fonte de custeio (Contribuição Compulsória), e com fortes restrições

\footnotetext{
${ }^{8}$ FERREIRA, A. C. Para uma concepção decente e democrática do trabalho e dos seus direitos (Re)pensar o direito das relações laborais. In: SOUSA SANTOS, B. A globalização e as ciências sociais. São Paulo: Cortez, 2002, p. 267-276.

${ }^{9}$ FERREIRA. Op. cit., p. 267-276.

${ }^{10}$ ATHAYDE CHAVES, L. Op. cit., p. 73-74.
} 
sobre o sistema de negociação coletiva e controle dos conflitos coletivos de trabalho, que se dão através dos Tribunais - o que só faz reduzir a autonomia dos trabalhadores e de seus sindicatos no processo de realização e criação dos direitos que lhes são pertinentes. ${ }^{11}$

Todos estes fatores alimentam a atitude de grande parte dos sindicalistas brasileiros, os quais, em sua maioria, não estão muito preocupados em compreender as transformações por que passa o mundo do trabalho, estando mais atentos às suas garantias, privilégios e vantagens pessoais do que ao futuro da própria categoria. ${ }^{12}$

Com base em todo o exposto, conclui-se que o sistema de relações de trabalho brasileiro, ademais de desrespeitar o princípio da liberdade sindical, inviabiliza a prática da negociação coletiva, concebida como um processo autocompositivo permanente e democrático de solução dos conflitos coletivos, baseados na dialética social. Faz-se, pois, necessário partirmos para mudanças neste sistema, que permitam que se inicie um processo gradual de transição do modelo estatutário vigente para o negocial, capaz de levar em consideração as disparidades econômicas, sociais e estruturais da realidade nacional e internacional.

\subsection{As diversas iniciativas de reforma do sistema sindical brasileiro}

Dentro deste enfoque de reestruturação das relações coletivas de trabalho no Brasil surgiram nos últimos anos diversas propostas para ordenar a reforma do sistema sindical brasileiro. Dentre as que iremos mencionar destaca-se a importante discussão sobre Contrato Coletivo de Trabalho, com as diferentes propostas que a compunham. Nos estenderemos um pouco mais a respeito da mesma, em face de que sua abordagem não se centrava somente na mudança do modelo sindical, mas incorporava novos e irrenunciáveis temas à agenda da mudança das relações de trabalho no Brasil, para a necessária revisão crítica da legislação trabalhista como um todo.

A expressão Contrato Coletivo de Trabalho foi resgatada por iniciativa da Central Única dos Trabalhadores (CUT) em 1988, quando da apresentação de um conjunto integral de propostas a Federação das Indústrias do Estado de São Paulo (FIESP), onde foram expostos posicionamentos a respeito de direitos sindicais, informações econômicas, mecanismos de participação, ruptura com o conceito de

\footnotetext{
${ }^{11}$ Para uma análise em profundidade da relação do movimento sindical brasileiro com o Estado, ver: CRIVELLI, E. Modelo corporativo no Brasil: ensaio para uma teoria da transição. Revista Políticas Públicas: o Estado e o Social. v. 11, n. 3, p. 1-26, jul./set. 1997.

${ }^{12}$ Neste sentido ver: TEIXEIRA DA COSTA, O. Novos rumos do sindicalismo no Brasil. Revista LTr. São Paulo, v. 61, n. 1, p. 34-39, jan./1997.
} 
data-base, negociação horizontal e eliminação do poder normativo da Justiça do Trabalho.

A partir desta proposta da CUT, o tema ganhou significativa relevância pública e o debate tomou corpo, se intensificando com a participação de entidades representativas de vários segmentos sociais. ${ }^{13}$

As principais alterações propostas neste debate a respeito da modernização das relações trabalhistas brasileiras passavam pela reformulação total do sistema vigente, por meio de um processo cuidadoso de transição para o sistema democrático, calcado na participação efetiva dos trabalhadores, na liberdade e autonomia sindical, na representação por local de trabalho, no exercício da negociação coletiva como instrumento efetivo de regulação bilateral do trabalho, na garantia do direito de greve, na desburocratização das leis trabalhistas, na rápida solução dos conflitos, nas alternativas voluntárias de composição dos conflitos coletivos e no redimensionamento do papel do Estado, que se tornaria apenas um regulador, organizador e fiador da efetiva liberdade sindical, abandonando, assim, seu caráter intervencionista.

Apesar de ser o objetivo fundamental das entidades que apoiavam esta proposta de modernização das relações de trabalho o de romper com o sistema corporativista que ainda vigora no Brasil e implementar um sistema democrático de relações de trabalho, baseado no regime de liberdade sindical e de direitos coletivos e na redefinição do papel do Estado, permitindo uma forma mais flexível e ágil de regulação, elas não perdiam de vista a noção da importância e da necessidade de fazê-lo com respeito aos princípios de ordem pública. O novo sistema de relações de trabalho deveria, conforme ressalta Siqueira Neto (1994), valorizar a negociação coletiva como fonte de criação do direito do trabalho, sem desprezar as fontes heterônomas, que deverão atuar em sintonia com os interesses dos agentes do mundo do trabalho. ${ }^{14}$

\footnotetext{
${ }^{13}$ Entre as quais Ministério do Trabalho, interlocutores sociais (principais entidades de representantes dos trabalhadores e dos empregadores), Ordem dos Advogados do Brasil (OAB), Associação Nacional dos Magistrados Trabalhistas (Anamatra) e Departamento Intersindical de Estatística e Estudos Sócio-Econômicos (Dieese), além de respeitáveis membros de Comissões Especializadas, tais como Amauri Mascaro Nascimento, Antônio Alvarez da Silva, José Francisco Siqueira Neto, Arnaldo Sussekind, Octávio Bueno Magano, Hugo Gueiros Bernardes, João de Lima Teixeira Filho e Arion Sayão Romita, dentre outros. Para maiores informações a respeito da evolução do debate sobre o Contrato Coletivo de Trabalho a partir da proposta inicial da CUT, inclusive as propostas legislativas apresentadas, ver: SIQUEIRA NETO, J. F. Contrato Coletivo de Trabalho no Brasil. Diferentes propostas, objetivos e finalidades. In: ALONSO DE OLIVEIRA, C. et alli (org.). O mundo do trabalho. Op. cit., p. 147-181.

${ }^{14}$ SIQUEIRA NETO, J. F. Contrato Coletivo de Trabalho no Brasil. Diferentes propostas, objetivos e finalidades. Do mesmo autor: Contrato Coletivo de Trabalho. Requisitos e condicionantes para sua implantação no Brasil. In: ALONSO DE OLIVEIRA, C. et alli (org.) O mundo do trabalho. Op. cit., p. $148-149$ e p. $233-263$.
} 
Sem embargo, ao cerne deste debate sobre o Contrato Coletivo de Trabalho levado a termo nos últimos anos, resultante da forte influência dos mais variados e distintos atores sociais que passaram a participar da discussão do tema, então de domínio público, começaram a incorporar-se teses críticas pontuais ao sistema de relações de trabalho vigente - quando, como bem ressalta Siqueira Neto (1994), o que pretendiam verdadeiramente era inserir na pauta a defesa de interesses outros, que não representavam verdadeiramente o desejo inicial de apresentar uma alternativa ao sistema de relações de trabalho brasileiro na perspectiva política de consolidação democrática, orientada no âmbito das relações trabalhistas pelos consagrados princípios internacionais da liberdade sindical.

Assim, os posicionamentos específicos de algumas entidades empresariais que, partindo do reconhecimento da necessidade de mudança do sistema de relações de trabalho vigente no Brasil, aproveitaram a oportunidade para inserir na agenda posicionamentos cujo objetivo prioritário era o de enfatizar e valorizar a negociação coletiva de trabalho em si, deslocando invariavelmente a questão da negociação no âmbito de centros normativos menores e periféricos relativamente ao centro normativo estatal, para entendê-la enquanto centro normativo único, independente do centro normativo estatal.

Esta postura permitiria alcançar uma ampla desregulamentação dos direitos coletivos e flexibilização dos direitos individuais, viabilizada pela total ausência do Estado na redefinição do ordenamento jurídico - ou seja, a mais absoluta privatização das relações de trabalho.

No outro extremo, alguns setores sindicais de trabalhadores, avessos às mudanças estruturais, aproveitaram a oportunidade para canalizar suas formulações no sentido de resistir contra todo e qualquer tipo de mudança que não se limitasse a adicionar ao padrão institucional existente um novo instrumento que propiciasse a incorporação de mais um nível negocial, sem no entanto discutir qualquer tipo de alteração no sistema estatutário vigente.

Finalmente, também o Poder Executivo, já sob forte influência neoliberal, apresentou vários Projetos de Lei, alguns dos quais basicamente consolidavam a idéia de Contrato Coletivo como instrumento exclusivo de valorização da negociação coletiva sem qualquer visão global do sistema de relações de trabalho, o qual é enganoso e superficial, pois as transformações e extinções de determinados institutos devem necessariamente ser processadas no contexto do sistema de relações de trabalho que se pretende implementar. ${ }^{15}$

\footnotetext{
${ }^{15}$ Siqueira Neto (1994) realiza uma análise minuciosa sobre a posição de cada um dos atores vinculados a cada macrogrupo em relação aos temas abrangidos pelas proposições, identificando-os e distinguindo-os em três propostas de Contrato Coletivo de Trabalho, numa sistemática que proporciona maior nitidez ao tema. SIQUEIRA NETO, J. F. Contrato Coletivo de Trabalho no Brasil. Diferentes propostas, objetivos e finalidades. In: ALONSO DE OLIVEIRA, C. et alli (org.). O mundo do trabalho. Op. cit., p. 156-181.
} 
A partir desta proposta de reforma trabalhista do governo e das várias críticas que recebeu, em especial às ausências sentidas e a transição dos sistemas, outros projetos de reforma foram surgindo, dentre os quais o Projeto de Reforma da Constituição e Transição da Estrutura Sindical da CUT, o qual buscava uma abrangência muito maior quanto aos institutos jurídicos reformulados, com uma preocupação específica quanto à questão das medidas que deviam reger o período de transição do modelo sindical corporativo para um sistema de relações de trabalho fundado em regras democráticas ${ }^{16}$, e outras propostas de reforma trabalhista, que em sua maioria propunham alterações nos artigos $8^{\circ}, 111$ e 114 do texto principal da Constituição Federal, que basicamente abrangem o instituto da liberdade sindical, o direito de ação dos sindicatos e o direito individual de ação dos trabalhadores, a competência da Justiça do Trabalho e as contribuições sindicais. ${ }^{17}$

Neste momento as discussões sobre a modernização das relações coletivas de trabalho e a reforma do modelo sindical brasileiro prosseguem, aumentando con-

\footnotetext{
${ }^{16}$ Projeto de Reforma da Constituição e Transição da Estrutura Sindical. 7. Versão. Central Única dos Trabalhadores - CUT. Agosto de 1998.

${ }^{17}$ Para uma análise mais detalhada ver: MASCARO NASCIMENTO, A. A reforma da legislação trabalhista. Revista LTr. São Paulo. v. 62, n. 11, nov. 1998. p. 1449-1461. Ver ainda, nesse sentido e em linhas gerais, a PEC 623/1998 - que previa a criação do Conselho da Justiça do Trabalho para funcionar junto ao TST e a instituição de instância extrajudicial prévia de mediação e conciliação, como condição para o ajuizamento de ação trabalhista individual; limitava a competência normativa da Justiça do Trabalho e atribuía-lhe competência para conflitos de direito sindical; proclamava a liberdade sindical, suprimindo a obrigatoriedade da representatividade sindical por categoria e do regime da unicidade sindical; eliminava a referência à contribuição sindical compulsória, à capacidade de votar e ser votado do aposentado filiado ao sindicato e suprimia também a contribuição confederativa, substituindo-a por contribuição devida ao sindicato pelos seus representados, fixada pela assembléia geral; a PEC 29/2003 - que, com as modificações propostas aos incisos II, III, IV e VIII do art. $8^{\circ}$, previa o reconhecimento pleno das centrais sindicais e das organizações nos locais de trabalho; a substituição processual sem limitações, abrangendo sindicato, federação, confederação ou central sindical; a obrigatoriedade de desconto e repasse aos sindicatos das contribuições voluntárias dos empregados e eliminação gradual da contribuição sindical, na proporção de $20 \%$ (vinte por cento) ao ano; a vedação da conduta anti-sindical, com previsão de tutela antecipada específica para reintegrar ao emprego ou anular qualquer ato de retaliação contra o trabalhador em virtude de sua participação na vida sindical e a eliminação da unicidade sindical, com a solução dos conflitos pela legitimidade para negociar, sendo resolvidos pelas centrais sindicais ou pela mediação e arbitragem; a PEC 369/2005 - que, em sua proposta de alteração dos arts. $8^{\circ}, 11,37$ e 114 da Constituição, propunha acabar com a unicidade sindical e o limite constitucional de base municipal mínima para o sindicato; punha fim à contribuição prevista em lei (que é o imposto sindical) e criava, nos limites autorizados pela legislação ordinária, a contribuição de "negociação coletiva"; mantinha em dispositivo constitucional o desconto em folha das contribuições associativas (mensalidades dos sindicalizados); assegurava a representação dos trabalhadores nos locais de trabalho na forma da lei; concedia às federações e confederações capacidade plena para promover negociações e acordos, e mantinha a exigência de comum acordo entre as partes para a propositura de dissídio coletivo perante a Justiça do Trabalho (EC 45/04).
} 
sideravelmente o grau de polêmica e de sutilezas do assunto. Isso impede, por um lado, a tomada de iniciativas conjuntas e o favorecimento de microrreformas normativas fragmentadas e desarticuladas, e por outro reflete o aprofundamento da crise do modelo sindical corporativo brasileiro, onde o único consenso é que o sistema de relações de trabalho atual não cumpre mais sua finalidade, devendo ser necessariamente repensado.

\section{Uma nova concepção de sindicalismo assente na cidadania e democracia participativa}

O movimento sindical, para enfrentar os grandes desafios que se apresentam, deve procurar, segundo Ricardo Antunes, novas possibilidades e formas de organização que possibilitem unir e articular horizontalmente os diversos segmentos que hoje compõem a classe trabalhadora e que estão desorganizados, criando um novo conceito de sindicalismo. ${ }^{18}$

Este sindicalismo deve ser efetivamente inclusivo no sentido de incorporar ao movimento os trabalhadores afastados de qualquer representação sindical, buscando a reinvenção do movimento sindical assente na idéia de solidariedade, emancipação social e democracia participativa como forma de "contrariar a tendência para a crescente dissociação entre padrões econômicos e sociais no mundo do trabalho", além de encetar uma busca por novos equilíbrios entre a ordem e a solidariedade social, da qual resulte uma "renovada combinação entre os princípios da regulação, do Estado, do mercado e da comunidade, num quadro de incremento da coesão e sustentabilidades sociais" $"$.

O debate em torno da reconstrução das relações laborais, de acordo com Sousa Santos (2002), demanda um novo senso comum político, jurídico e epistemológico, um senso comum participativo e emancipatório, que se torna condição essencial para superar o paradigma da modernidade, qual seja a auto-reprodução do capitalismo enquanto modo hegemônico de produção e suas formas de conhecimento nos pilares da regulação e da emancipação.

A tensão entre os princípios emancipação-regulação, segundo o autor, se deve a que os direitos sociais desenvolvidos no período do capitalismo organizado, caracterizado pela passagem da cidadania cívica e política para o que foi designado por

\footnotetext{
${ }^{18}$ ANTUNES, Ricardo. Adeus ao trabalho? Ensaios sobre a metamorfose e a centralidade do mundo do trabalho. São Paulo: Cortez e Moraes, 1995, p .62-63

${ }^{19}$ FERREIRA, Antonio Casimiro. Para uma concepção decente e democrática do trabalho e dos seus direitos. (Re)pensar o direito das relações laborais. In: SOUSA SANTOS, B. A globalização e as ciências sociais. São Paulo: Cortez, 2002. p. 287.
} 
“cidadania social”, isto é, a conquista de significativos direitos sociais no domínio das relações de trabalho, da segurança social, da saúde, da educação e da habitação por parte das classes trabalhadoras, das sociedades centrais (de um modo menos característico e intenso, por parte de alguns setores das classes trabalhadoras em alguns países periféricos e semiperiféricos), teve lugar no marco da democracia liberal. ${ }^{20}$

E, por este motivo, acabam sendo a expressão da integração política das classes trabalhadoras no Estado capitalista, significando o "aprofundamento da regulação em detrimento da emancipação", fazendo com que "as lutas pela cidadania social tenham culminado na maior legitimação do Estado capitalista", em detrimento de novas formas de cidadania não-liberais e não-estatizantes, em que seja possível uma relação mais equilibrada com a subjetividade. ${ }^{21}$

Este processo histórico do desenvolvimento da cidadania social sofre, segundo o autor, uma verdadeira transformação nestas últimas décadas, marcada especialmente pela formulação de alternativas mais ou menos radicais ao modelo de desenvolvimento econômico e social do capitalismo e de afirmação política de novos sujeitos sociais.

\footnotetext{
${ }^{20}$ SOUSA SANTOS, Boaventura. Pela mão de Alice. O social e o político na pós-modernidade. São Paulo: Cortez, 1995. p. 246-249. Para uma análise mais profunda sobre a tensão entre regulação/ emancipação vide: SOUSA SANTOS, Boaventura. Crítica da razão indolente. Contra o desperdício da experiência. v. 1. Para um novo senso comum: a ciência, o direito e a política na transição paradigmática. São Paulo: Cortez, 2002. Na obra, o autor explica os princípios e lógicas de que são constituídos os pilares da regulação e da emancipação. O pilar da regulação é constituído por três princípios ou lógicas, quais sejam: o princípio do Estado, que consiste na obrigação política vertical entre cidadãos e Estado; o princípio do Mercado, que consiste na obrigação política horizontal individualista e antagônica entre os parceiros do mercado; e o princípio da Comunidade, que consiste na obrigação política horizontal solidária entre membros da comunidade e entre associações. O pilar da emancipação é constituído por três lógicas de racionalidade, quais sejam: a racionalidade estéticoexpressiva, das artes e da literatura; a racionalidade cognitiva-instrumental, da ciência e da tecnologia; e a racionalidade moral-prática, da ética e do direito. Segundo o autor, o paradigma da modernidade como projeto pretendeu "um desenvolvimento harmonioso e recíproco do pilar da regulação e do pilar da emancipação" e também que esse desenvolvimento se traduzisse "indefectivelmente pela completa racionalização da vida coletiva e individual". Essa dupla vinculação entre os dois pilares, e entre eles e a práxis social, garantiria a "harmonização de valores sociais potencialmente incompatíveis, tais como justiça e autonomia, solidariedade e identidade, igualdade e liberdade". Porém, segundo Sousa Santos, a ousadia de propósito tão vasto foi a semente de seu próprio fracasso, com promessas incumpridas e déficits irremediáveis, surgindo a idéia de transição paradigmática proposta como uma nova forma de conhecimento, a que denomina "conhecimento-emancipação", como semente de um novo senso comum capaz de sustentar a inteligibilidade e as lutas emancipatórias na transição paradigmática (p. 50-97).

${ }^{21}$ SOUSA SANTOS, BOAVENTURA. Pela mão de Alice. O social e o politico na pós-modernidade. São Paulo: Cortez, 1995. p. 250-255.
} 
A partir dai, e ainda segundo Santos, "os partidos e os sindicatos tiveram de confrontar-se permanentemente com as formas organizativas de novos movimentos sociais", que para além da "fragmentação e globalização da produção, e da despolitização e da naturalização dos imperativos econômicos" e da "indiferenciação entre produção e reprodução", inserem-se na luta pela emancipação social e legítima criação de novos sujeitos sociais de base transclassista". Estas novas "práticas de mobilização social" reorganizam as novas energias emancipatórias pautadas na idéia de "obrigação política horizontal, entre cidadãos, e a idéia de participação e da solidariedade concretas na formulação da vontade geral", suscetíveis de "fundar uma nova cultura política e uma nova qualidade de vida pessoal e coletiva assentes na autonomia e no autogoverno, na descentralização e na democracia participativa, no cooperativismo e na produção socialmente útil". ${ }^{22}$

Neste sentido, Casimiro Ferreira (2002), ao defender a reinvenção e renovação do movimento sindical como fator de democratização do trabalho e como reforço da voz coletiva, busca sustentação em Boaventura de Sousa Santos, que ressalta ser necessário

[...] reconstruir as políticas de antagonismo social de modo a conferir ao sindicalismo um novo papel na sociedade, um sindicalismo mais político, menos sectorial e mais solidário, um sindicalismo de mensagem integrada e alternativa civilizacional, onde tudo liga com tudo: trabalho e meio ambiente; trabalho e sistema educativo; trabalho e feminismo, trabalho e necessidades sociais e culturais de ordem colectiva; trabalho e Estado-Providencia; trabalho e terceira idade; etc. Em suma, a acção reivindicativa não pode deixar de fora nada do que afecte a vida dos trabalhadores e dos cidadãos em geral. ${ }^{23}$

\section{Considerações finais}

Esta é, no momento, a tônica das discussões em torno da mudança da estrutura sindical e do sistema negocial no Brasil. Muitos são os questionamentos e indefinições, porém, neste contexto de adaptações e transformações realmente necessárias, em face das mudanças no mundo do trabalho no confuso e indefinido cenário econômico dos dias atuais, por um lado, e da estrutura do sistema de rela-

\footnotetext{
${ }^{22}$ SOUSA SANTOS, Boaventura. Pela mão de Alice. O social e o político na pós-modernidade. São Paulo: Cortez, 1995. p. 256-264.

${ }^{23}$ FERREIRA, Antonio Casimiro. Para uma concepção decente e democrática do trabalho e dos seus direitos. (Re)pensar o direito das relações laborais. In: SOUSA SANTOS, B. A globalização e as ciências sociais. São Paulo: Cortez, 2002. p. 291.
} 
ções de trabalho brasileiro, por outro, deveria preponderar a ênfase na consolidação de um sistema de relações de trabalho democrático, que priorize o aumento da participação dos trabalhadores na administração cotidiana das relações de trabalho e na necessidade de redefinição do padrão institucional e do ordenamento jurídico.

E que deste novo modelo saiam, então, sindicatos fortalecidos, com mecanismos e práticas participativas dos trabalhadores nas tomadas de decisões empresariais, que atue como verdadeiro contrapoder no âmbito das relações coletivas de trabalho, possibilitando, assim, a criação de um autêntico e democrático modelo de negociação coletiva, que assegure uma equivalência na estipulação entre trabalhadores e empresários, e a definição de um novo padrão, que não comprometa o resultado e a qualidade das relações de trabalho no Brasil, os quais devem verdadeiramente fundar-se nos princípios de justiça social.

Que o novo sindicato transforme-se num interlocutor fortalecido e co-participante, aumentando a possibilidade de interação, negociação e diálogo entre os atores sociais (especialmente em um momento onde o papel dos colaboradores e suas competências atingem uma nova dimensão face à implementação de uma gestão flexível, com maior eficiência e produtividade), criando a possibilidade de que o interesse coletivo e o interesse privado possam interagir em outro patamar, tornando possível combinar eficiência com eqüidade, gestão democrática e obtenção de recursos e valores de capital, com atuações também assentes em valores humanos.

Junto à necessidade de rever a discussão das modificações das estruturas nas relações coletivas de trabalho, inserindo-as na lógica de democratização das relações trabalhistas e nos princípios de liberdade sindical, ${ }^{24}$ internacionalmente adotados, não deveríamos desperdiçar a oportunidade que esta reestruturação propicia para inserir elementos de renovação e reinvenção de um novo sindicalismo, assente na cidadania, solidariedade e emancipação social, para que junto aos demais movimentos sociais persiga a consecução de um modelo político de democracia participativa.

Afinal, conforme alerta Sousa Santos (2002), a ambigüidade e complexidade do tempo presente demandam um novo senso comum político, jurídico e epistemológico, um senso comum participativo e emancipatório, condição essencial para enfrentar o colapso da ordem ou desordem existente das sociedades capitalistas, que permitirá desenhar novos campos analíticos mais vastos e mais incompletos, que realcem as "várias formas de opressão nas sociedades capitalistas, ao mesmo tempo em que abrem novos espaços para uma política cosmopolita, para diálogos interculturais, para a defesa da autodeterminação e da emancipação, espaços possibilitados pela globalização das praticas sociais", formulando "um conjunto de interrogações radicais sobre as sociedades capitalistas contem-

${ }^{24}$ Convenção ${ }^{\circ} 87$ da OIT, até hoje não ratificada no Brasil. 
porâneas e o sistema mundial que as integra, de forma a abrir caminho para a dupla reinvenção, exigida pela própria transição paradigmática, de um novo senso comum emancipatório e de uma nova subjetividade individual e coletiva com capacidade e vontade de emancipação". ${ }^{25}$

$\mathrm{E}$, finalmente, com o reconhecimento de que estas novas formas de sociabilidade, novas subjetividades coletivas e emancipatórias, migrarão desde o âmbito do espaço da produção até o âmbito da comunidade, levando ao fortalecimento da sociedade civil, da participação política e da democracia em geral.

\section{Referências}

ANTUNES, Ricardo. Adeus ao trabalho? Ensaios sobre a metamorfose e a centralidade do mundo do trabalho. São Paulo: Cortez e Moraes, 1995.

ATHAYDE CHAVES, L. As mudanças no mundo do trabalho e seus reflexos sobre a atmosfera sindical. Trabalho \& Doutrina. São Paulo. n. 15, p. 71, dez./ 1997.

CRIVELLI, E. Modelo corporativo no Brasil: ensaio para uma teoria da transição. Revista Políticas Públicas: o Estado e o Social. v. 11, n. 3, p. 1-26, jul./set. 1997.

FERREIRA, Antonio Casimiro. Para uma concepção decente e democrática do trabalho e dos seus direitos. (Re)pensar o direito das relações laborais. In:

SOUSA SANTOS, B. A globalização e as ciências sociais. São Paulo: Cortez, 2002.

FREITAS JR. A. R. Globalização, Mercosul e crise do estado-nação.

Perspectiva para o direito numa sociedade em mudança. São Paulo: LTR. 1997.

LEITE, M. Reestruturação produtiva, novas tecnologias e novas formas de gestão de mão de obra. In: OLIVEIRA, A. et alli (org.). O mundo do trabalho. Crise e mudança no final do século. São Paulo: Página Aberta, 1994.

MASCARO NASCIMENTO, A. Questões atuais de direito do trabalho. Revista LTR, São Paulo, v. 61, n. 1, p.15-17, jan.1997.

. A reforma da legislação trabalhista. Revista LTr. São Paulo. v. 62, n. 11, nov. 1998.

\footnotetext{
${ }^{25}$ SOUSA SANTOS, Boaventura. A crítica da razão indolente: contra o desperdício da experiência. v. 1. Para um novo senso comum: A ciência. O direito e a política na transição paradigmática. São Paulo: Cortez, 2002. p. 329-333.
} 
MATOSO, E. J. L. O novo e inseguro mundo do trabalho nos países avançados. In: OLIVEIRA, A. et alli (org.). O mundo do trabalho. Crise e mudança no final do século. São Paulo: Página Aberta, 1994.

RIFKIN, J. O fim dos empregos. O declínio inevitável dos níveis dos empregos e a redução da força global de trabalho. São Paulo: Makron, 1995.

SEVERO ROCHA. L. (org.). Teoria do direito e do estado. Porto Alegre: Sérgio Antônio Fabris, 1994.

SIQUEIRA NETO, J. F. Contrato coletivo de trabalho no Brasil. Diferentes propostas, objetivos e finalidades. In: OLIVEIRA, A. et alli (org.). O mundo do trabalho. Crise e mudança no final do século. São Paulo: Página Aberta, 1994.

SOUSA SANTOS, Boaventura. Pela mão de Alice. O social e o político na pósmodernidade. São Paulo: Cortez, 1995.

. Crítica da razão indolente. Contra o desperdício da experiência. v.

1. Para um novo senso comum: a ciência, o direito e a política na transição paradigmática. São Paulo: Cortez, 2002.

TEIXEIRA DA COSTA, O. Novos rumos do sindicalismo no Brasil. Revista LTr. São Paulo, v. 61, n. 1, p. 34-39, jan./1997. 